\title{
Formación religiosa católica en la familia colombiana: de la libertad a la responsabilidad ${ }^{*}$
}

\author{
Dukeiro de Jesús Ruíz Amaya ${ }^{* *}$
}

Recibido: 30 de noviembre de 2011 Evaluado: 2 de febrero de 2012 Aceptado: 11 de abril de 2012

\section{RESUMEN}

El presente artículo es una exhortación a los padres de familia, sobre el derecho de libertad religiosa existente en Colombia, para que asuman la responsabilidad que tienen de educar a sus hijos menores de edad en la fe que ellos profesan, teniendo en cuenta que así como "los padres son responsables de la existencia de los hijos, son también responsables de todo aquello que los hijos necesitan para vivir de manera digna" (Fagothey, 1990). Esta tarea debe ser asumida con libertad por ser un compromiso de todo bautizado, el cual no puede ser delegado ni asumido por otras personas o instituciones, aunque se cuente con el apoyo de la Iglesia, la escuela, el Estado colombiano y la sociedad civil en general.

\section{Palabras clave}

Familia católica, formación religiosa católica, fe, libertad, responsabilidad.

* El presente artículo de investigación es producto del macroproyecto: Educación Religiosa Escolar y Formación integral, desarrollado durante cuatro años por los estudiantes y docentes de la Licenciatura en Filosofía y Educación Religiosa de los semestres séptimo a décimo y dirigido por el doctor Dukeiro Ruíz Amaya, en la Facultad de Educación de la USTA, 2006 - 2009.

** Docente de la Universidad Santo Tomás, Bogotá, Facultad de Educación y de la Fundación Universitaria los Libertadores, Bogotá. Ph.D. en Narrativa y Ciencia. Doctor en Derecho Canónico. Magíster en Derecho Canónico y en Filosofía Latinoamericana. Licenciado en Teología y en Filosofía. Correo electrónico: dukeiroruiz@hotmail.com 


\title{
Catholic Religious Education in Colombian Families: from Freedom to Responsibility
}

\author{
Dukeiro de Jesús Ruíz Amaya
}

\begin{abstract}
This article is a call to parents, in accordance with the religious freedom that exists in Colombia, so that they take responsibility for educating their underage children in the faith that they profess. And this, taking into account that "parents are responsible for both their children's existence as well as for everything the children need to live in dignity" (Fagothey, 1990). This duty must be freely assumed by them, since it is a commitment of every baptized person. It may not be delegated nor assumed by any other person or institution, although church, school, Colombian State and civil society are there to support them in a general way.
\end{abstract} Aceptado: 11 de abril de 2012

\section{KEYWORDS}

Catholic family, catholic religious education, faith, freedom, responsibility. 
Hijos, obedeced a vuestros padres en el Señor; porque es justo. Honra a tu padre y a tu madre, tal es el primer mandamiento que lleva consigo una promesa: para que seas feliz y se prolongue tu vida sobre la tierra. Padres, no exasperéis a vuestros hijos, sino formadlos más bien mediante la instrucción y la corrección según el Señor.

(Ef. 6, 1-4)

\section{INTRODUCCIÓN}

Teniendo en cuenta la normatividad que sobre libertad religiosa existe en Colombia,

la formación en la fe no es tarea de la escuela y por ende la educación religiosa que se brinda en las instituciones educativas, no la reemplaza, aunque lo ideal es que la complemente, sabiendo que son los padres de familia los primeros responsables de la educación de sus hijos (Ruíz et ál., 2010).

Por ello, es necesario invitar a los padres de familia para que asuman de manera libre pero con responsabilidad dicho deber. El presente artículo comprende los siguientes subtemas: relación formación-educación, formación religiosa católica: concepto, finalidad, la libertad y la responsabilidad de los padres de familia de formar a sus hijos en la religión, según sus creencias. El trabajo de campo gira en torno a una narración respecto de la manera como en una familia boyacense, católica, tradicional y practicante, durante cinco generaciones, se ha dado educación religiosa libremente a sus miembros, donde se resalta el testimonio de vida, manifestado en diversas prácticas religiosas. Finalmente, se presentan algunas alternativas que pueden ser implementadas en las familias, para que la formación religiosa católica en Colombia no decaiga y sean los padres de familia quienes al formar a los hijos en la religión que ellos profesan, lo hagan de manera libre, responsable y siendo coherentes entre lo que piensan, dicen ser y hacen como miembros de la Iglesia católica.

\section{RELACIÓN FORMACIÓN-EDUCACIÓN}

El concepto "formación" proviene de la palabra latina formatı̌o, por ende, se trata de la acción y efecto de formar o formarse. "formación" significa "ascenso a la humanidad", es decir, desarrollo del hombre, en tanto hombre (Orozco, 2000, p. 12); en este sentido,

la formación es lo que queda, es el fin perdurable; a diferencia de los demás seres de la naturaleza, el hombre es un proyecto, un devenir, un ser en busca de perfección, no somos obras concluidas, por tanto, la condición de la existencia humana temporal es formarse, integrarse, convertirse en un ser espiritual capaz de romper con lo inmediato y lo particular, y ascender a la universalidad a través del trabajo y de la reflexión filosófica, partiendo de las propias raíces (Flórez, 1974).

Formar es generar desde dentro el cambio con miras a ser "sí mismo", a ser "uno mismo". La palabra "educación" procede de los verbos latinos educare y educere, que son constitutivos del concepto educatio. Educare significa: conducir, crear, nutrir, alimentar, instruir, y educere significa: orientar, guiar, conducir, transportar, sacar, extraer de adentro hacia afuera (Diccionario ilustrado Latino-español, 2000; Villalobos, 2004). Por esta razón, el acto educativo no busca solo facilitar al hombre la interiorización de los objetivos propuestos, de tal manera que domine cognitivamente unos contenidos considerados fundamentales, sino también, la consecución del propio fin del ser humano: su autonomía personal. En consecuencia, 
educar al hombre significa, por una parte, permitirle autoeducarse $y$, por otra, capacitarle para que tome por sí mismo decisiones razonables (Ruíz, 2004, p. 118).

En consecuencia educación y formación son tareas complementarias: la educación es una alternativa de formación de los seres humanos, porque es un dispositivo y un soporte de la formación, un punto de partida tendiente a facilitar el camino que ha de recorrer quien se está educando en compañía del educador.

La formación es un compromiso insoslayable, impostergable e irrenunciable, que la única persona responsable de ella es uno mismo y que la educación es un medio para la formación, sin embargo no es el único. La formación es construcción de la existencia humana (García, 2010).

\section{Formación religiosa católica}

Si la fe es concebida como "la virtud teologal por la cual creemos en Dios y en todo aquello que Él nos ha dicho y revelado y que la Santa Iglesia nos propone creer, porque Dios es la misma verdad" (CCE, 1814), la respuesta del creyente, frente a la Revelación de Dios no es otra que la fe, por la cual "el hombre se entrega entera y libremente a Dios", ayudado por su gracia y por los auxilios del Espíritu Santo a través de los dones $(\mathrm{DV}, 5)$.

\section{Concepto de formación religiosa católica}

En el contexto católico, la formación religiosa o formación en la fe, es sinónimo de evangelizar, es decir: llevar la Buena Nueva a todos los ambientes de la humanidad $\mathrm{y}$, con su influjo, transformar desde dentro, renovar a la misma humanidad, teniendo en cuenta que la finalidad de la evangelización implica un cambio interior que se refleja en la conciencia colectiva de los hombres, por ser una actividad en la que ellos están comprometidos, su vida y ambientes concretos (EN, 18).

La acción de formar en la fe significa "llevar a vivir desde la plenitud, a encontrarse consigo mismo para ir al encuentro con el trascendente, el Absoluto" (Cuenca, 2010).

En efecto, cuando se habla de formación religiosa católica a los hijos, se hace referencia a un acto imaginado, deseado e intencionado, no es impuesto y menos agregado, no se reduce a una acción ejercida por un educador, como es el caso de la educación religiosa escolar, porque la persona que se forma adquiere, desarrolla y/o perfecciona sus capacidades (García, 2007 y Guillén, 1997), es la persona misma, como sujeto, quien decide o no formarse, al ser un trabajo continuo, dinámico, perseverante, que busca la perfección, en cuanto tiene un sentido de conquista y tiende a trascender como sujeto histórico que no se agota en el saber del mundo ni en el saber sobre sí mismo. Es decir, no es informar, sino formarse y transformarse porque se trata de "la construcción de la personalidad, del nacimiento del cristiano no solo de una "actualización" de su identidad. No de una información sobre la fe, sino de una transformación radical del ser, de una nueva concepción de la existencia" (Cañizares y del Campo, 1999), según el querer de Cristo "Vosotros, pues, sed perfectos como es perfecto vuestro Padre celestial" (Mt. 5,31), es tender hacia el encuentro con Dios Padre y con la mediación de la Iglesia, como le sucedió a Pablo de Tarso 
cuando afirmó: “. .. y no vivo yo, sino que es Cristo quien vive en mí" (Gal. 2, 20).

\section{Finalidad de la formación religiosa católica}

La tarea o misión de la Iglesia Católica es la evangelización según el mandato de Cristo: "Id, pues, y haced discípulos a todas las gentes bautizándolas en el nombre del Padre y del Hijo y del Espíritu Santo" (Mt. $28,1)$ y en su quehacer resalta la labor de la familia como "Iglesia doméstica" donde los niños reciben de sus padres y de otros familiares cercanos las semillas de la fe, gracias a las enseñanzas de la Iglesia católica a través de la catequesis, la predicación de la Palabra y las prácticas religiosas.

La formación religiosa católica por parte de los padres, tiene una finalidad concreta, en cualquiera de las etapas del desarrollo de la persona humana, de manera especial cuando se trata de inculcar los principios de la doctrina a los niños y jóvenes: para que aprendan la doctrina y vivan de acuerdo con el querer o voluntad de Dios: el "ser santos" (1 Tes. 4,3).

La formación religiosa, anteriormente se limitaba a repetir de memoria algunas oraciones y parte de la doctrina, teniendo como referente las enseñanzas del catecismo del Padre Astete y la historia sagrada, ahora, es parte fundamental en los planes de pastoral de las parroquias, con personas capacitadas que conocen la doctrina y aplican elementos de pedagogía que hacen más motivante, interesante, dinámica y enriquecedora la formación en la fe.
La tarea de formar es una manera concreta de apostolado que se debe desarrollar en cada familia, es decir,

El apostolado se desarrollará sobre todo dentro de la propia familia, con el testimonio de la vida vivida conforme a la ley divina en todos sus aspectos, con la formación cristiana de los hijos, con la ayuda dada para su maduración en la fe, con la educación en la castidad, con la preparación a la vida, con la vigilancia para preservarles de los peligros ideológicos y morales por los que a menudo se ven amenazados, con su gradual y responsable inserción en la comunidad eclesial y civil, con la asistencia y el consejo en la elección de la vocación, con la mutua ayuda entre los miembros de la familia para el común crecimiento humano y cristiano, etc. (FC No. 71).

La Iglesia brinda a los padres de familia los medios oportunos para la educación de sus hijos en la fe. Una catequesis orgánica y sistemática de iniciación cristiana, donde se atiende a la preparación y celebración de los sacramentos, y tantas iniciativas parroquiales y de grupos apostólicos, llaman a los padres a disponer las cosas para que sus hijos puedan disfrutar de tales medios, que se adaptarán a su edad y a sus circunstancias.

\section{Libertad religiosa en Colombia}

En el aspecto religioso, desde 1991, el Estado colombiano es aconfesional, plural y laico, pero es garante de la libertad de cultos, teniendo como único límite la protección del derecho de los demás en el ejercicio de sus libertades públicas y derechos fundamentales: "Toda persona tiene derecho a profesar libremente su religión y a difundirla en forma individual o colectiva. Todas las confesiones religiosas e iglesias son igualmente libres ante la ley" (Constitución 
Política de 1991, Art. 1-4, 19) y reconoce a los padres de familia el derecho de escoger el tipo de educación para sus hijos menores, precisando que en los establecimientos del Estado ninguna persona podrá ser obligada a recibir educación religiosa como tampoco será obligada a practicar actos de culto o a recibir asistencia religiosa contraria a sus convicciones personales (Art. 68).

En consecuencia, toda persona tiene derecho a recibir asistencia religiosa de su propia confesión en donde quiera que se encuentre, principalmente en los lugares públicos (centros médicos, cuarteles militares, los lugares de detención), como también a recibir e impartir enseñanza e información religiosa, elegir para sí y los padres para los menores o los incapaces bajo su dependencia, dentro y fuera del ámbito escolar, la educación religiosa y moral según sus propias convicciones (Ley 133 de 1994, Art. 6).

En relación con los niños, la educación es considerada como un derecho fundamental, pero no absoluto, por lo cual ha requerido el apoyo de la Corte Constitucional y otras instancias internacionales como se indica a continuación. El derecho a la educación en los niños

Adquiere[n] carácter fundamental cuando su titular es un menor de edad debido a que los niños y niñas fueron elevados constitucionalmente a sujetos merecedores de un tratamiento prioritario y especial por parte de la familia, la sociedad y el Estado. La condición física y mental del niño convoca la protección especial del Estado y le concede validez de acciones y medidas para mitigar su situación de debilidad, propulsando el principio de igualdad (Sentencia T-002/92).
En el caso de las familias católicas este derecho es contemplado en la ley canónica al indicar que a los hijos les obliga una vez celebrado el Sacramento del Bautismo (c 849) a llevar una vida congruente con la doctrina evangélica, tal como se indica en lo referente a las obligaciones y derechos de todos los fieles cristianos (cc. 208-223) y los derechos y obligaciones de los fieles cristianos laicos (cc. 224-231, 1366). La obligación y el derecho de los padres de educar a los hijos, implica la elección de los medios e instituciones, el apoyo de la iglesia católica de manera especial de los pastores (cc. 773-780), los cuales deben disponer lo necesario para que todos los fieles reciban educación católica (cc. 793-794, 821).

El derecho a la libertad religiosa no siempre se ha hecho efectivo:
El ejercicio de los derechos dimanantes de la libertad religiosa y de cultos, tie- ne como único límite la protección del derecho de los demás al ejercicio de sus libertades públicas y derechos funda- mentales, así como la salvaguarda de la seguridad, de la salud y de la mora- lidad pública, elementos constitutivos del orden público, protegido por la ley en una sociedad democrática (Ley 133 de 1994, Art. 4).

La libertad de practicar, individual o colectivamente, los cultos, devociones y ceremonias propios de su credo religioso y la difusión de los criterios y principios que conforman la doctrina espiritual a la que él se acoge (Constitución Política de 1991, Art. 19) no son absolutas, porque

encuentran sus límites en el imperio del orden jurídico, en el interés público y en los derechos de los demás. Su ejercicio abusivo, como el de cualquier otro derecho, está expresamente proscrito por 
el artículo 95, numeral 1, de la Constitución (Sentencia T-200 de 1995).

\section{La educación religiosa católica de los hijos, responsabilidad de los padres de familia}

La maternidad y la paternidad responsables están relacionadas con el mandato bíblico referido a los esposos cuando contraen matrimonio y finalizando el consentimiento: "De manera que ya no son dos, sino una sola carne. Pues bien, lo que Dios unió no lo separe el hombre" (Mt. 19, 6), lo cual implica un compromiso respecto de las funciones unitaria y procreativa de los esposos, por ser uno de los fines del sacramento del matrimonio (c. 1055,1), es por ello que "los hijos tienen derecho a que los padres les brindemos nuestro apoyo permanente y les garanticemos la mejor herencia: buen ejemplo, óptima educación y excelente formación" (Fradique-Méndez, 2007). Lo anterior, tiene su razón de ser desde la ley canónica porque el matrimonio "está ordenado por su misma índole natural al bien de los cónyuges y a la generación y educación de la prole" (c. 1055) y teniendo en cuenta que las enseñanzas de Dios se transmiten ante todo de padres a hijos: "Queden en tu corazón estas palabras que yo te dicto hoy. Se las repetirás a tus hijos, les hablarás de ellas tanto si estás en casa como si vas de viaje, así acostado como levantado" (Dt. 6,6-7).

Según la Iglesia Católica:

Todo niño gozará del derecho a tener acceso a educación en materia de religión o convicciones conforme con los deseos de sus padres o, en su caso, sus tutores legales, y no se le obligará a instruirse en una religión o convicciones contra los deseos de sus padres o tutores legales (Tomasi, 2011).

La obligación de educar a la prole en la familia, es de tanta trascendencia que, cuando falta, difícilmente puede suplirse. Es, pues, deber de los padres crear un ambiente de familia animado por el amor, por la piedad hacia Dios y hacia los hombres, que favorezca la educación íntegra personal y social de los hijos. "La familia es, por tanto, la primera escuela de las virtudes sociales, que todas las sociedades necesitan" (GE, 3). En consecuencia, el bautizado tiene a su vez la obligación de participar en la actividad apostólica y misionera del pueblo de Dios (CCE, 1269 y 1270) mediante la vivencia del amor, la gracia y los carismas, tanto en la vida de la sociedad eclesial como en cada uno de los miembros que forman parte de la misma (Juan Pablo II, 1983), de tal manera que la acción evangelizadora de la Iglesia de ir por todo el mundo a predicar el evangelio para que la humanidad conozca el ofrecimiento gratuito de Cristo, sea evidente, buscando siempre "la salvación de los hombres" (c. 1752).

\section{Para el Magisterio Eclesiástico:}
la verdadera educación se propone la formación de la persona humana en orden a su fin último y al bien de las sociedades de las cuales el hombre es miembro y en cuyas responsabilidades tomará parte cuando llegue a ser adul- to (GE.1).

Y es auténtica, si busca el desarrollo armónico de las condiciones físicas, morales e intelectuales y se apoya en la antropología, psicología, pedagogía y didáctica. Esta tarea debe complementarse con la catequesis por ser "una instrucción elemental de los niños en la fe cristiana dentro de la parroquia, 
teniendo como objetivo la iniciación y maduración en la fe del creyente dentro de la comunidad cristiana" (Aparecida, 302), los contenidos deben tener en cuenta que:

respondan al propio fin, al propio carácter, al diferente sexo, y que sea conforme a la cultura y a las tradiciones patrias y al mismo tiempo esté abierto a las relaciones fraternas con otros pueblos, a fin de fomentar en la tierra la unidad y la paz (GE, 1).

La anterior normatividad es reiterada en el Código de infancia y adolescencia: "El Estado fomentará por todos los medios la estabilidad y el bienestar de la familia como célula fundamental de la sociedad" (Art. 6). Y más adelante agrega:

Es obligación de la familia, de la sociedad y del Estado, formar a los niños, niñas y adolescentes en el ejercicio responsable de los derechos. Las autoridades contribuirán con el derecho a través de decisiones oportunas y eficaces y con claro sentido pedagógico (Art. 15).

Finalmente se recuerda que:

la educación permanente de la fe, es un asunto que atañe a toda la comunidad. Es una acción educativa de toda la Iglesia, realizada a partir de la responsabilidad peculiar de cada miembro de la comunidad en un contexto o clima comunitario rico en relaciones, para que los cristianos se incorporen activamente a la vida de dicha comunidad (Directorio General para la Catequesis, No. 222).

\section{Formación RELIGIOSA CATÓLICA EN LA FAMILIA COLOMBIANA}

Este apartado consta de dos partes: la primera narra a manera de ejemplo la forma como una familia de tradición católica, ha realizado durante cinco generaciones la formación religiosa católica; la segunda es el análisis de la narración anterior (figura 1).

\section{Figura1. Templo del Municipio de San Mateo,}

Boy

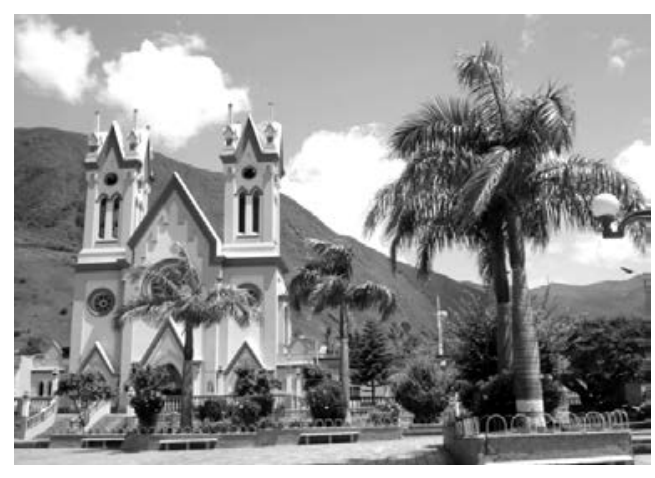

Fuente: recuperado de http://www.deverano. net/615/sitios-turisticos/san-mateo-boyaca/

\section{Narración sobre formación religiosa católica ${ }^{1}$}

\section{Familia Reyes Tarazona}

- Mis papitos se casaron por la Santa Iglesia. Tuvieron seis hijitos: tres parejitas y nos bautizaron pequeños. Después hicimos la Primera Comunión y la Confirmación. Se iba al pueblo a hacer los primeros viernes. La Semana Santa era de oración, de procesiones cargando los pasos, mis papitos eran Priostos porque pagaban los estipendios y llevaban estandartes y pabellones. No se

1 Este apartado corresponde a un trabajo de campo realizado por el autor del presente artículo, en el Departamento de Boyacá, durante los últimos seis meses, en diálogos con miembros de las diversas generaciones, identificadas con los apellidos de las familias: Reyes Tarazona, Amaya Reyes, Ruíz Amaya, López Ruíz, Ruíz López, los cuales permitieron reconstruir parte de las memorias de las familias en relación con la formación religiosa dada en cada una de ellas. Lo presentado es una síntesis de lo relacionado con la formación en la fe. Los diálogos se realizaron con Asunción Reyes Tarazona (93 años), Concepción Amaya Reyes (81 años), Martha Amaya (76 años), Gloria Ruíz (57 años) y Sandra López (33 años). 
escuchaba música, ni se podía cantar ni hacer trabajos pesados.

Mi papito nos enseñó en cuestión de religión lo que mis abuelos les habían enseñado. Todo era de memoria, se repetían las oraciones como el Padre Nuestro, el Ave María, la Salve, el Credo y muchas más que no recuerdo. Nunca supimos que era leer la Biblia porque no se podía ni tener en la casa. El 7 de diciembre en la noche todas las hijas de María, íbamos al pueblo para participar en las vísperas de la fiesta de la Inmaculada Concepción del día 8, había rosario de aurora y a las cinco de la mañana alborada, a las diez de la mañana, la Santa Misa y procesión por las calles con la banda del pueblo. En la tarde regresábamos a la casa.

Cada dos años venían misioneros que iban por las veredas y reunían a la comunidad en las escuelas para enseñar catecismo, preparaban la gente para que se confesara, celebraban la Misa y predicaban, pero hacían llorar a muchos por lo que les decían sobre los pecados y por no arrepentirse. Aconsejaban pedir perdón y tener enmienda. Pocas veces iba uno al pueblo a misa los domingos. Nos inculcaron la devoción a la Virgen Santísima, de manera especial a la Inmaculada Concepción, a la Virgen del Milagro y a la Virgen de Chiquinquirá. Por eso, se hacían romerías tanto a la Uvita, al Santuario de la Virgen del Tabor o del Milagro y a Chiquinquirá a las fiestas patronales. Se organizaba con tiempo, se caminaba todo el viaje de ida y de vuelta. Se llevaban cargas de comida: amasijo, carnes secas, harinas, panela, cuajadas y granos. Otras cosas se compraban de camino. En donde se daba posada se cantaban las salves, se rezaba el Santo Rosario y se le pedía a la Virgen que nos ayudara a salir de la guerra de los Mil días porque acabó con muchos hombres buenos, inocentes y valiosos.

En los Santuarios uno se confesaba, participaba en varias misas, pero solo se comulgaba una vez. Se pagaban las mandas en plata que se le ofrecía a la Virgen, se pagaban las Salves y algunas misas en acción de gracias. Se compraban recuerdos para traer a los cuidanderos: rosarios, escapularios, cuadros de la Virgen, imágenes en bulto, estampas y novenas. De regreso se oraba para agradecer a Dios lo contenta que había estado la gente y lo animadas que estaban las fiestas. A Nuestro Amo Santísimo, las gracias porque ha tenido misericordia de nuestras familias.

\section{Familia Amaya Reyes}

En la casa fuimos siete hermanos, nos criamos todos con mis papacitos quienes eran casados por la Iglesia (figura 2). Mi papacito nos enseñó a todos a leer y a escribir. Sobre lo que pregunta de la manera como nos enseñaron y aprendimos la religión, recuerdo, que primero nos enseñaron a repetir las oraciones como el Padre Nuestro, el Ave María, la Salve y el Credo. Cuando fuimos creciendo nos enseñaron a rezar el Santo Rosario y todas las noches a la hora de acostarnos se hacía el de quince casas que eran tres rosarios en uno con los misterios gozosos, dolorosos y gloriosos. Algunas veces nos quedábamos dormidos. 
Figura 2 Descendientes de la Familia Amaya Reyes

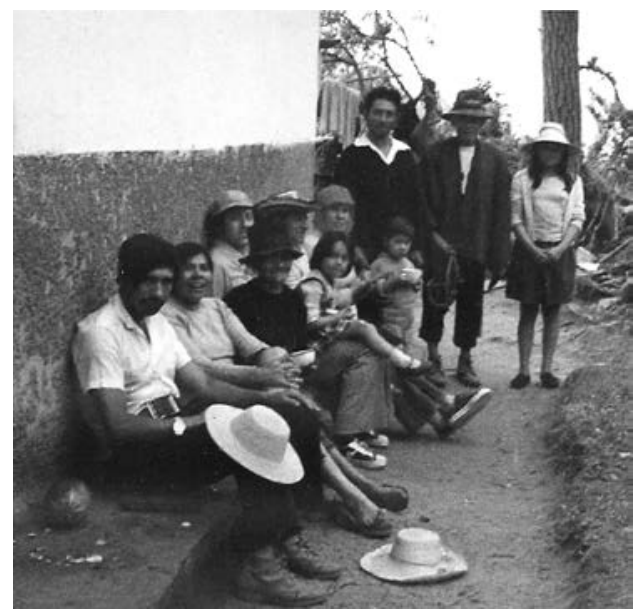

Fuente: tomada del álbum de la familia Ruíz Amaya.

Cuando ya aprendimos a leer, había un catecismo del Padre Astete que repasábamos, el cual tenía una cantidad de preguntas y sus respectivas respuestas. Eso se aprendía de memoria. Nos aprendimos también las cien lecciones de historia sagrada que eran relatos bíblicos narrados en forma de cuento. Uno leía y los demás escuchaban. Esos pasajes nos gustaban mucho porque nos imaginábamos las escenas de relatos como el diluvio, el paso del Mar Rojo, las guerras, la zarza ardiente, la manera como hacían los sacrificios y ofrendas que se daban, el nacimiento del Niño Jesús, la visita de los pastores, el llamado a los doce apóstoles, los milagros y las parábolas, como también todo el juicio, su muerte y resurrección (Establecimientos Benzinger \& Co, S.A., 1952).

Lo que se enseñaba, se aprendía y se practicaba porque le repetían, que eso era para salvarse, según dice el catecismo del Padre Astete: "es un compendio simple de lo que el cristiano debe saber y cumplir para salvarse" (CCE, Introducción). Se hacían cuarenta horas, misiones cada dos años y la comunidad se reunía en las escuelas, se obligaba a celebrar los primeros viernes del mes y a asistir a la misa cada ocho días, uniformados y formados. Todos debíamos obedecer y aprender lo que el Padre explicaba en el Sermón porque durante la semana de clases los profesores nos pasaban al tablero y delante de todos uno tenía que decir lo que había entendido. El que no lo hacia era castigado.

\section{Familia Ruíz Amaya}

En casa somos cuatro hijos: dos mujeres y dos varones. La formación religiosa católica que recibimos tuvo tres protagonistas: el hogar, la escuela y la parroquia Nuestra Señora de Chiquinquirá (figura 3).

\section{Figura 3. Concepción Amaya}

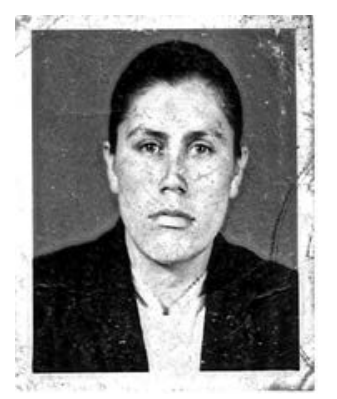

Fuente: tomada del álbum de la familia Ruíz Amaya.

- En el hogar: era práctica, mediante el aprendizaje de memoria de las oraciones y de los misterios del Santo Rosario que se hacía todos los días en la noche, antes de acostarnos a dormir. Otra cosa fue la lectura de la Sagrada Escritura, el estudio del Catecismo de la Iglesia Católica (CCE), de la novena de navidad y de la celebración de los sacramentos de iniciación (bautismo, primera comunión y confirmación). Todos íbamos a misa ya fuera al Pueblo cada ocho días o aquí en la vereda a la Hacienda del padre Ramón de Jesús Mojica. 
- En la escuela: en la clase de religión que se enseñaba en primaria y la daban los profesores y luego en la Escuela Normal, que la daban los capellanes, se enseñaba doctrina y a la vez se hacían prácticas como el rosario diario en mayo, siendo el 13 de mayo muy solemne, el capellán presidía las eucaristías $\mathrm{y}$ todos los domingos en el templo, a la cual nos llevaban formados y con el uniforme de gala. Debíamos aprendernos el Evangelio y las ideas sobre lo que predicaba porque nos tomaban a todos la lección y se calificaba.

- Finalmente en la parroquia Nuestra Señora de Chiquinquirá: por medio de la catequesis que recibimos como preparación para la celebración de algunos sacramentos como la Eucaristía y la Confirmación. También, los cuatro hijos formamos parte del los grupos juveniles y pastorales de la parroquia donde los sacerdotes nos preparaban como catequistas y colaboradores para poder ir a las veredas con el padre a animar los grupo haciendo dinámicas, cantando y explicando.

\section{Familia López Ruíz}

Aunque somos practicantes de la religión católica, a mis hijos los crié con mayor libertad, pese a haberlos bautizado pequeños. Con los años y cuando comprendían se les enseñaron algunas oraciones como el Padre Nuestro, el Ave María, la Salve y el Credo. La Primera Comunión y la Confirmación la hicieron más grandes, cuando ya comprendían y podían asumir los compromisos como creyentes. Se leía la Palabra de Dios y se meditaba y estudiaron el catecismo de la Iglesia Católica.
La vivencia de ellos, en cuestión de fe y de coherencia de vida, se desarrolló bien porque eran partícipes activos de la vida en comunidad: pertenecían a la Infancia Misionera, luego al grupo juvenil, iban a la catequesis, apoyaban algunos trabajos y apostolados de la parroquia, pero al crecer, y alcanzar la mayoría de edad, aparentemente todo se fue al piso, no quieren saber nada de "curas" ni de religión. No participan de la oración del Santo Rosario ni de la lectura y reflexión de la Palabra que se hace todos los días en la casa. Eso me ha dado muy duro, pero los he puesto en cadena de oración para que Dios con su santo poder me los bendiga siempre, los guíe y ayude a salir adelante. La excusa que tienen es que no hay tiempo, que tienen mucho quehacer. Hay momentos en que me preocupan más de la cuenta, pero tengo una madre y abogada a quien se los encomiendo y eso me da tranquilidad: Es la Inmaculada Concepción. Han cambiado mucho las cosas, eso se refleja en la manera como son mis nietos.

\section{Familia Ruíz López}

Como me ha tocado hacer de papá y de mamá, educar hijos en la fe, no es fácil, dados todos los cambios, desafíos y problemas que hay y a los cuales se deben enfrentar las nuevas generaciones a diario. A mi hijo lo bautizamos pequeño y le enseñé a orar, a leer y meditar textos de la Sagrada Escritura, a participar de la Santa Misa, a hacer obras de caridad y a ser servicial (figura 4). 
Figura 4. Catalina y Esteban Ruíz

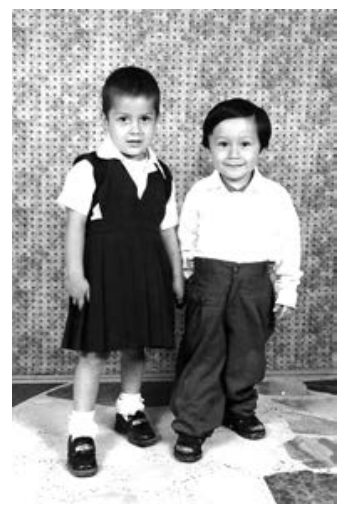

Fuente: tomada del álbum de la familia Ruíz Amaya.

A la edad de diez años hizo la Primera Comunión y asistía a la Eucaristía todos los domingos, luego fue a la catequesis y se preparó para hacer la Confirmación, pero, no se confirmó. No se qué sucedió, pero ahora se ha vuelto indiferente, si es que va a la Eucaristía se queda en la puerta del templo, ya no se confiesa ni comulga, se queda mudo. No le gusta nada y al preguntarle, critica el comportamiento de los sacerdotes y el de "las viejas rezanderas" porque dice que no dan testimonio de lo que dicen ser. Estoy preocupada y tendré que hablar con el párroco a ver cómo me ayuda.

\section{Análisis de las narraciones anteriores}

El cuidado que dan los padres a los hijos no se limita a lo temporal y material sino que incluye lo espiritual, lo trascendente y en el caso de los creyentes católicos al haber recibido esa fe que Dios mismo ha revelado a través de su hijo Jesús, es necesario reconocer que en una cultura impregnada de cristianismo, lo religioso, aporta a la madu- ración de la personalidad, brinda elementos que le ayudan a discernir y a juzgar críticamente las realidades sociales y situaciones límites y se traduce en actitudes y modos concretos de conducta y de convivencia, que son peculiares en las personas creyentes (Pujol, 2001).

La educación religiosa que se brinda, aunque es básica, proporciona elementos fundamentales y es acorde con el querer de la Iglesia católica cuando pide a los padres que transmitan a sus hijos, su propia experiencia de fe:

Los hijos educando su libertad, a fin de que ellos busquen y hallen por sí mismos el bien más grande de su vida, aquello que da razón a todos los sacrificios y sustenta la esperanza, pudiendo así encontrar personalmente el "esplendor de la verdad" que es el Señor (Pontificia Comisión para América Latina, 2007).

Se constata que los padres conocen y asumen la responsabilidad de la formación religiosa de sus hijos, pero ayudados por sus familias, la Iglesia católica, la escuela y la comunidad en general.

Respecto de la manera como se realiza la educación religiosa, sus contenidos, forma de enseñanza memorística y las prácticas que se tienen, se nota que han dado cambios y se ha pasado, por ejemplo, del no poder leer y meditar la Palabra de Dios a ser la Sagrada Escritura un "Libro de cabecera" para estudiar la Palabra diariamente y del asistir y participar algunos días a la Santa Misa, al asistir con indiferencia y simplemente como espectador, según la última familia que fue consultada. 


\section{Algunas alternativas para FORMAR EN RELIGIÓN A LOS HIJOS HOY}

Muchas veces se ha criticado la labor educativa que se hace en la Iglesia católica a la cual se acusa de no estar a la par con los retos, novedades y moda que imponen los cambios culturales. Lo anterior tiene efectos de manera especial en las nuevas generaciones, de manera particular en lo religioso, siendo necesario proponer algunas alternativas que ayuden a consolidar las semillas religiosas que hay en cada persona y le permitan la madurez en su fe.

El testimonio de vida auténticamente cristiana y entregada a Dios en la persona del prójimo es definitivo y fundamental como una manera concreta del "amor a Dios y al prójimo como a nosotros mismos" (Mt. 22, 37-39). Es responsabilidad de los padres, de su convencimiento, de su libertad y compromiso esencial e irrenunciable si lo hacen como testigos de la obra que Dios ha hecho en ellos, porque no es suficiente decir que se cree si en la vida diaria no se demuestra: pues la fe sin obras es muerta (St. 2,17), teniendo en cuenta que

\begin{abstract}
en el seno de una familia, la persona descubre los motivos y el camino de pertenecer a la familia de Dios. El gran tesoro de la educación en la fe consiste en la experiencia de una vida familiar que recibe la fe, la conserva, la celebra, la transmite y testimonia (Aparecida 118).
\end{abstract}

La familia como iglesia doméstica y en el contexto de la libertad religiosa, cumple la misión de formar en la fe a los hijos, a través de "la educación religiosa y la catequesis" que la sitúan en el ámbito de la Iglesia como un verdadero sujeto de evangelización y de apostolado (Consejo Pontificio para la Familia, 2006).

La educación religiosa dada en las familias debe tener presente la formación de la persona para la vida, según los valores humanos y cristianos propuestos por Jesucristo en el Evangelio, para impregnar la cultura actual de la civilización del amor (Juan Pablo II, 1986), mediante la palabra y el ejemplo diarios, delegando responsabilidades y permitiendo espacios de una auténtica libertad, la entrega sincera de sí, el cultivo del respeto del otro, el sentido de la justicia, la acogida cordial, el diálogo, el servicio generoso, la solidaridad y los demás valores que ayudan a vivir la vida como un don (Pontificio Consejo para la Familia, 2006).

La educación para el servicio debe ser fundamental, de tal manera que se haga con el convencimiento que el hombre vale más por lo que es que por lo que tiene, donde el servicio al prójimo se concrete en las actitudes del "buen samaritano" quien se conmueve del sufrimiento de su prójimo: lo reconoce, se compadece, lo acoge, lo cura, lo lleva y lo deja en un sitio seguro asumiendo el compromiso de responder por él. "El hombre no puede encontrar su propia plenitud si no es en la entrega sincera de sí mismo a los demás [...] Buen samaritano es el hombre capaz precisamente de ese don de sí mismo" $(\mathrm{SD}, 28)$. Buen samaritano es aquel capaz de actuar frente a toda actividad en favor de los hombres que sufren y de todos los necesitados de ayuda (Juan Pablo II, 1984).

El protagonismo de la educación religiosa de los hijos debe ser de los dos cónyuges, quienes deben reflexionar sobre las virtudes y los valores morales y religiosos que unen a su familia y deben ser transmitidos a sus hijos. 
No abandone injustamente a su esposa, la tarea de formar humana y religiosamente a sus hijos. En cada una de estas áreas, el hombre y la mujer se complementan en sus esfuerzos. A medida que forma a sus hijos, oriente la vista de ellos hacia el Reino de Cristo y hacia una vida vivida desde una perspectiva sobrenatural (Mons y Mayers, 2012).

\section{Conclusión}

Al ser los hijos, bendición de Dios hecha vida, los padres asumen la obligación de educarlos, porque

la tarea educativa tiene sus raíces en la vocación primordial de los esposos a participar en la obra creadora de Dios; ellos, engendrando en el amor y por amor una nueva persona, que tiene en sí la vocación al crecimiento y al desarrollo, asumen por eso mismo la obligación de ayudarle eficazmente a vivir una vida plenamente humana (Pontificio Consejo Justicia y Paz, p. 96).

La verdadera educación intenta la formación de la persona humana en el orden a su último fin y al bien de las sociedades. La misión de educar que corresponde a la Iglesia es parte del deber de anunciar a todos los hombres el camino de la Salvación.

El derecho que tienen los niños y adolescentes a la protección integral se materializa "en el conjunto de políticas, planes, programas y acciones que se ejecutan en los ámbitos nacional, departamental y municipal con la correspondiente asignación de recursos financieros, físicos y humanos" (Fradique-Méndez, 2007). En el caso de Colombia, dentro de la política estatal de primera infancia, está como una de las líneas estratégicas el promover

[la] educación inicial la cual tendrá como marco conceptual el enfoque de competencias para la primera infancia y orientaciones pedagógicas, las cuales favorecerán la creación de ambientes tempranos de aprendizaje no escolarizados, que incluyan como elemento fundamental el juego, el arte, la literatura y demás lenguajes expresivos, el papel de la familia, el afecto y la promoción del buen trato (Ministerio de Protección Social, pp. 3-4).

La fe debe encarnarse en la cultura:

Una fe que no se hace cultura es una fe no acogida plenamente, no pensada por entero, no fielmente vivida. La fe compromete al hombre en la totalidad de su ser y de sus aspiraciones. Una fe que se situase al margen de lo humano, $y$, por tanto, de la cultura sería infiel a la plenitud de cuanto la palabra de Dios manifiesta y revela, una fe decapitada, más aún, una fe en proceso de disolución (Juan Pablo II, 1986).

La libertad de manifestar su religión o sus creencias solo podrá ser objeto de las limitaciones prescritas por la ley que sean necesarias para proteger la seguridad, el orden, la salud o la moral públicos o los derechos y libertades fundamentales de terceros (Convención Internacional sobre los Derechos del Niño, 1959, Art. 14, 3).

En síntesis, si hay una formación religiosa desde la infancia, los hijos seguirán creciendo con razones y motivaciones para continuar ese proceso de madurez, no solo en edad cronológica sino intelectual y afectiva, teniendo en cuenta los cimientos que desde la formación en la fe recibieron, siendo servidores en el estado de vida que ellos libremente definan.

\section{Referencias}

BAC (1966). Concilio Vaticano II. Madrid.

Biblia de Jerusalén. Bilbao: Desclée de Brouwer. 
Cañizares, A. y Del Campo, M. (1999). Evangelización, catequesis, catequistas. Madrid: EDICE.

CCE (2000). Catecismo de la Iglesia Católica. Bogotá: San Pablo.

Celam (2010). Aparecida (4⿳a a ed.). Bogotá.

Cenalmor, D. y Miras, J. (2004). El derecho de la Iglesia. Eunsa-Celam. Bogotá.

Congregación para la Doctrina de la Fe (2004). Carta a los obispos de la Iglesia Católica sobre la colaboración del hombre y la mujer en la Iglesia y el mundo.

Congregación para el Clero (1997). Directorio general para la catequesis. Bogotá.

Corte Constitucional. Sentencia de Tutela 002/92, 8 de mayo y Sentencia de Tutela 200/1995, 9 de mayo.

Cuenca, R. (2009). Educación de la fe en la familia. Artículo. Docente investigador UTPL mediador de conflictos proyectos ILFAM.

Diccionario de la lengua española (22⿳ㅗ. ed.) (2010). Madrid: Espasa Libros.

Diccionario ilustrado latino-español, españollatino (8ª . ed.) (2000). Barcelona: Spes.

Establecimientos Benzinger \& Co. S.A. (1952). Historia sagrada. Suiza: Einsideln.

Flórez, R. (1994). Hacia una pedagogía del conocimiento. Bogotá: McGraw-Hill.

Fradique-Méndez, C. (2007). Código de infancia y adolescencia. Bogotá: Grupo Editorial Ibáñez.

García, M. (2007). Formación, concepto vitalizado por Gadamer. México, D. F.: Castellanos Editores.

Guillén, J. (1986, noviembre). El Estado y la libertad educativa. Revista Universitas Canonica, vol. 7, año VI, núm. 14, 17-26. Pontificia Universidad Javeriana - Facultad de Derecho Canónico.
Juan Pablo II (1981). Familiaris consortio. Exhortación apostólica. Roma.

Juan Pablo II (1986, 30 de noviembre). Mensaje mundial a la juventud.

Madrid-Malo, M. (1992, junio) La libertad religiosa en la Constitución de 1991. Revista Universitas Canonica, vol. 13, año XII, núm. 23, 23-45. Bogotá: Pontificia Universidad Javeriana - Facultad de Derecho Canónico.

Madrid-Malo, M. (1998). Constitución Politica de Colombia. Bogotá: 3R Editores.

Ministerio de Educación Nacional. Ley 133 de 1994.

Ministerio de la Protección Social; Ministerio de Educación Nacional; Instituto Colombiano de Bienestar Familiar (2007). Política pública nacional de primera infancia. "Colombia por la primera infancia" [documento Compes Social, 109]. Bogotá.

Myers, J. (2012, 21 de mayo). Padre enseña a los hijos tu fidelidad. En Carta pastoral sobre los padres y la paternidad. Peoria.

Orozco, L. (2000). Responsabilidad y compromisos del docente en la formación integral. Bogotá: Universidad Santo Tomás.

Pontificio Consejo para la Familia (2006, 25 de abril).

Ruíz, D. (2004). Formación integral, según el c. 795 [monografía]. Bogotá: Pontificia Universidad Javeriana.

Tomasi, S. [arzobispo] (2011, 10 de marzo). No se puede educar contra las creencias de los padres. Recuperado el 4 de marzo de 2011, de http://www.zenit.org/article38475? =spanish

Villalobos, E. (2004). Didáctica integrativa y el proceso de aprendizaje. Bogotá: Trillas. 